\title{
Liquen plano oral y síndrome vulvovaginal- gingival. A propósito de un caso
}

\section{Lichen planus and vulvovaginal-gingival syndrome. Clinical case}

\author{
Alonso Rosado A*, Hernández Hernández E**, Mateos Rodríguez R**, \\ Pérez Gómez RM***, Bascones Martínez A****
}

\section{RESUMEN}

El liquen plano es una enfermedad mucocutánea crónica común, que afecta habitualmente a la mucosa oral, pero que en ocasiones otras mucosas como la vaginal pueden también afectarse. Sin embargo, la afectación concomitante de las mucosas oral y vaginal, conocida como síndrome vulvovaginal-gingival del liquen plano es una manifestación poco común, caracterizada por erosión y descamación en la vulva, vagina y encías.

Debido a la posibilidad de afectación de otras mucosas así como la capacidad para malignizarse que tiene el liquen plano, enfatizamos la importancia que tiene su diagnóstico correcto, así como el seguimiento continuo de los pacientes afectados por liquen oral en la clínica dental. Nos proponemos como objetivo presentar el caso clínico de una paciente de mediana edad que acudió a nuestra consulta a la que se le diagnosticó liquen plano oral y, tras varios años de evolución, presenta síndrome vulvovaginal-gingival de liquen plano oral.

Palabras clave: Liquen plano, síndrome vulvovaginal-gingival, malignización.

\section{SUMMARY}

Lichen planus is a common mucocutaneous disease that affects at oral mucosa, but sometimes other mucosal surfaces are affected like vulvar mucosa. However, lichen planus with concomitant oral and genital involvement called vulvovaginal-gingival syndrome, is a rare condition characterized by erosions and desquamation of the vulva, vagina and gingival.

Cause is probably that oral lichen planus affects any other mucosa, and these lesions have the potential to become malignant, we think that is very important an appropriate diagnosis of these patients. Our aim is to present a clinical case of a female patient with vulvovaginal-gingival syndrome.

Key words: Lichen planus, vulvovaginal.gingival syndrome, malignant.

Fecha de recepción: 17 de julio de 2009.

Aceptado para publicación: 22 de julio de 2009.

* Médico estomatólogo. Doctor en Medicina y Cirugía. Máster en Periodoncia. Profesor asociado USAL.

** Licenciada en Odontología.

*** Diplomada en Enfermeria. Supervisora del servicio de Ginecología HCU Salamanca. Prof Asociado escuela de Enfermeria USAL.

**** Catedrático de Medicina Bucal y Periodoncia UCM.

Alonso Rosado A, Hernández Hernández E, Mateos Rodríguez R, Pérez Gómez RM, Bascones Martínez A. Liquen plano oral y síndrome vulvovaginal-gingival. A propósito de un caso. Av. Odontoestomatol 2010; 26 (5): 235-241. 


\section{INTRODUCCIÓN}

\section{Definición y epidemiología (1)}

El liquen plano (LP) es una enfermedad inflamatoria crónica, de etiología desconocida (aunque se reconoce una base autoinmune) (2, 3), mucocutánea con manifestaciones orales muy frecuentes, con una clínica e histología características y bien definidas $(2,4,5)$ y de curso evolutivo benigno aunque en ocasiones puede llegar a sufrir una degeneración maligna (5-12).

Presenta una prevalencia menor al $4 \%$, con predominio por el sexo femenino a partir de los 50 años (2).

Aunque la mucosa oral es la principalmente afectada, puede presentarse una manifestación polimucosa que se conoce como síndrome vulvovaginal-gingival, y se caracteriza por lesiones en vulva, vagina y encías, siendo una manifestación muy poco frecuente, presentándose en torno al 0,1\%.

\section{Etiología}

Aunque se entiende que el liquen plano es una enfermedad idiopática, por muchos es apoyada la idea de que esta manifestación se ve afectada por unos factores predisponentes (genética) (2-4) y unos factores desencadenantes (factores psíquicos, fármacos, materiales estomatológicos, virus, etc...) (2).

\section{Clínica}

De manera muy esquemática las presentaciones clínicas del liquen plano oral son:

1. Liquen plano blanco

- Reticular.

- En placa.

2. Liquen plano rojo

- Atrófico.

- Erosivo.

Otros autores $(2,4,13)$, describen otras manifestaciones más atípicas como son el liquen zooniforme, anular, Nigricans, y penfigoide.
Aunque la mucosa oral es la principal y primariamente afectada, también pueden verse afectas otras mucosas como la vaginal, entendiéndose en tal caso como síndrome vulvovaginal-ginvival del liquen plano, que es el centro de nuestro artículo.

\section{Diagnóstico}

Según la OMS en 1978, los criterios clínicos e histopatológicos que se han de cumplir para el diagnóstico de liquen plano son los siguientes $(2,4)$ :

\section{Criterios clínicos}

- Presencia de lesiones bilaterales y mayormente simétricas.

- Presencia de estriado blanco reticulopapular.

- Lesiones erosivas, atróficas, ampollares y en placas (siempre en presencia en otro lugar de la mucosa oral de estrías blancas).

\section{Criterios histopatológicos}

- Presencia de infiltrado inflamatorio yuxtaepitelial en banda.

— Signos de degeneración hidrópica del estrato basal.

— Ausencia de displasia epitelial.

Si no se cumplen estos aspectos en su totalidad, no hablaremos de liquen plano oral sino de lesiones liquenoides orales $(2,4)$.

\section{Tratamiento $(2,4-7,13-15)$}

El tratamiento farmacológico de elección son los corticoides tópicos, tales como el propionato de clobetasol que será aplicado en aquellas lesiones que cursen con dolor o quemazón, (principalmente las lesiones rojas), dejando sin tratar farmacológicamente las lesiones anodinas (blancas generalmente). La corticoterapia será retirada paulatinamente cuando mejoren los síntomas, y no se prolongará más de 6 meses seguidos. El tratamiento con inmunosupresores, tales como el tacrólimus no presenta pros frente a la terapia corticosteroidea (2) en contra de lo que pueden pensar otros autores, (15) hoy en día se considera que se prefiere la terapia con corticoesteroides retirados paulatinamente. 
La terapia quirúrgica, servirá de ayuda para realizar la biopsia excisional.

Nos parece necesario resaltar la vital importancia de un seguimiento periódico y continuo del paciente, para vigilar las lesiones y la exploración del resto de mucosas en colaboración con los profesionales médicos indicados en cada caso.

\section{PACIENTE. MATERIAL Y MÉTODOS}

Presentamos el caso de una paciente mujer, de 44 años de edad que acudió a nuestra consulta en 1996. Ama de casa. No fumadora. En tratamiento antidepresivo desde hacía 2 años. Sin otros antecedentes de interés en relación con su enfermedad actual.

Desde hace meses presenta lesiones en toda la mucosa oral que la paciente describió como úlceras o llagas que le producían dolor y escozor, con brotes de exacerbación y mejora.

A la exploración clínica presentaba lesiones blanquecinas reticulares en ambas mucosas yugales sobre un fondo de apariencia eritematosa (Figs. 1 y 2).

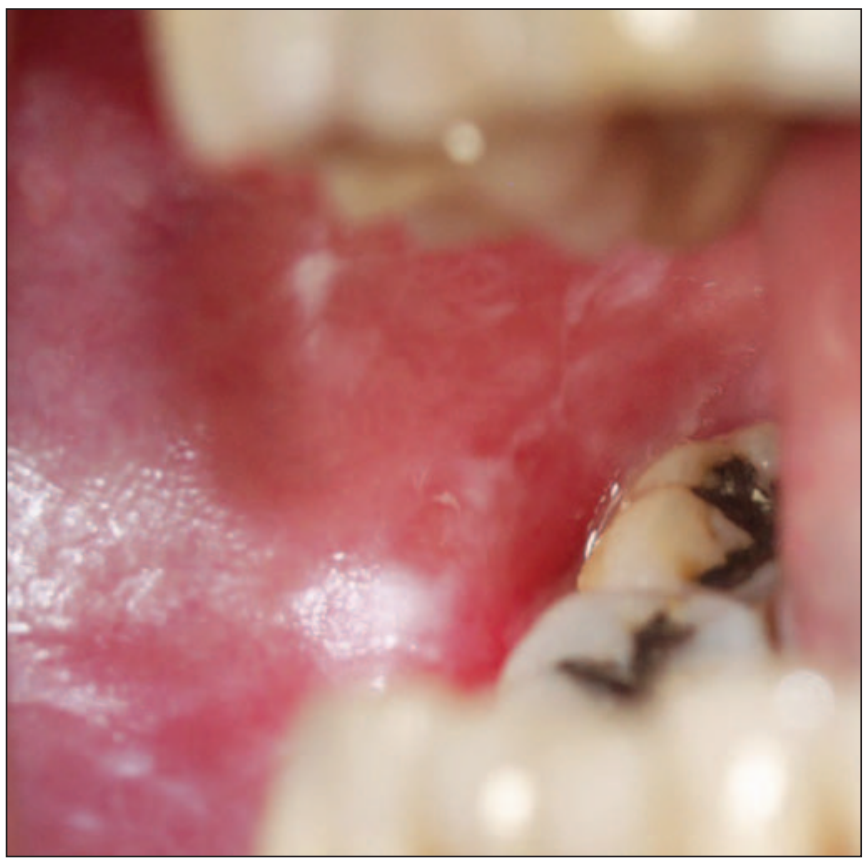

Fig.1. Mucosa yugal derecha.

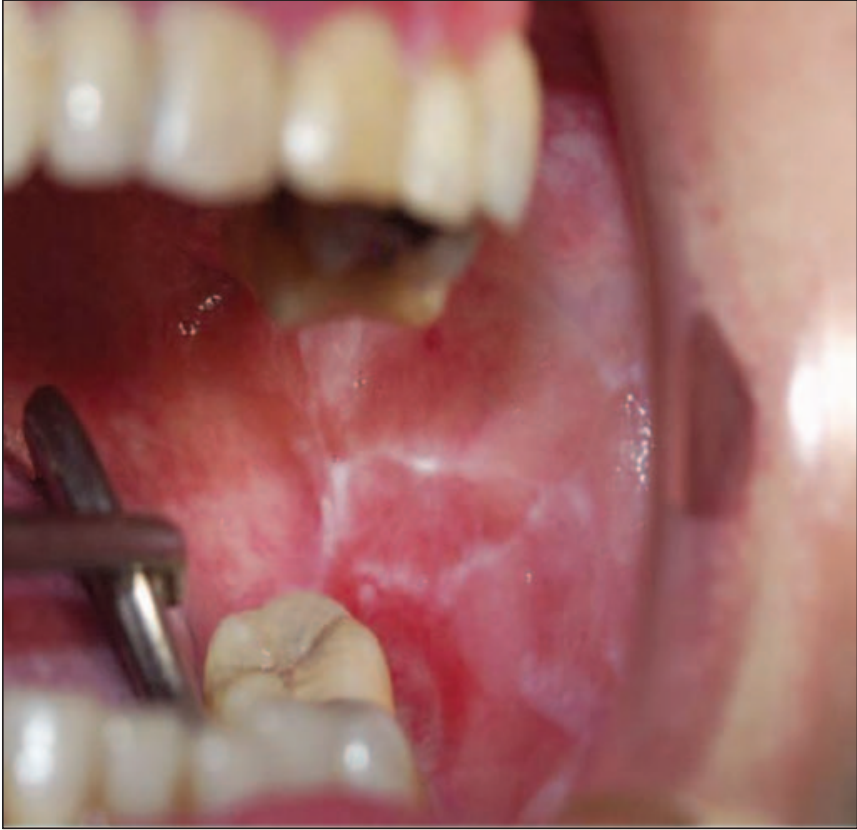

Fig.2. Mucosa yugal izquierda.

Dichas lesiones también son visibles en paladar (Fig. 3), dorsolingual (Fig. 4), y mucosa gingival (Figs. 5 y 6). La mucosa gingival se desprende fácilmente apareciendo el sangrado característico de gingivitis descamativa (Fig. 7).

Se le realizó una exploración oral completa bajo luz artificial, utilizando sonda periodontal CP 8/11 para

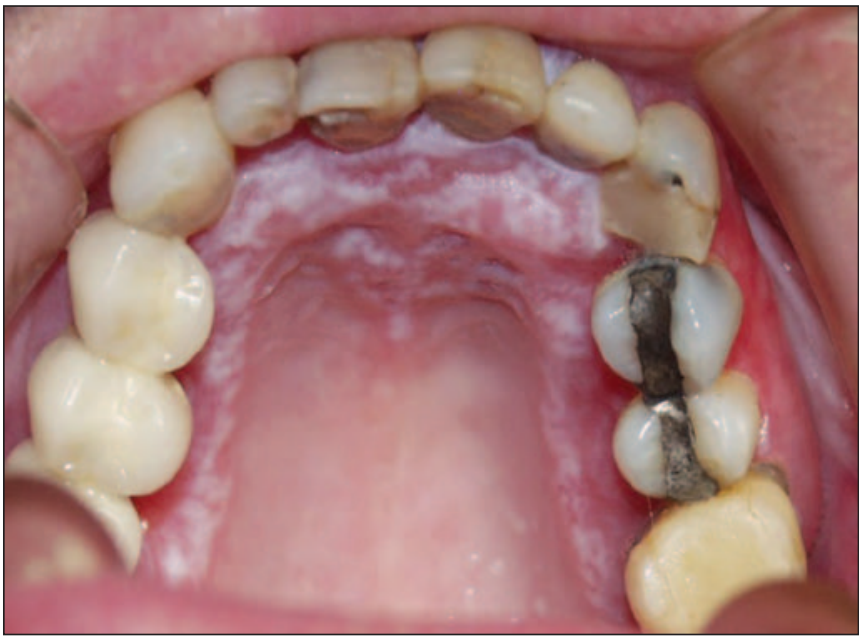

Fig.3. Mucosa palatina. 


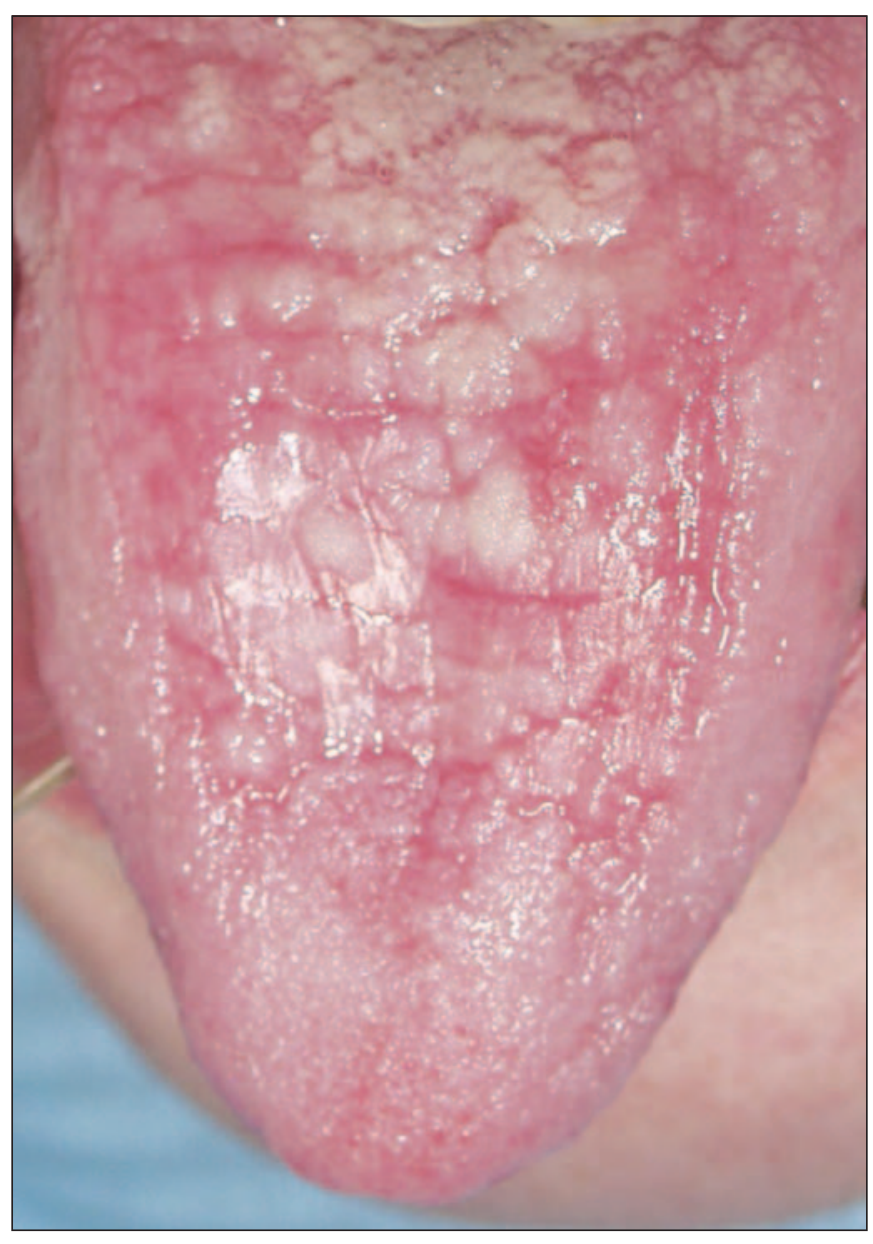

Fig. 4. Dorso lingual.

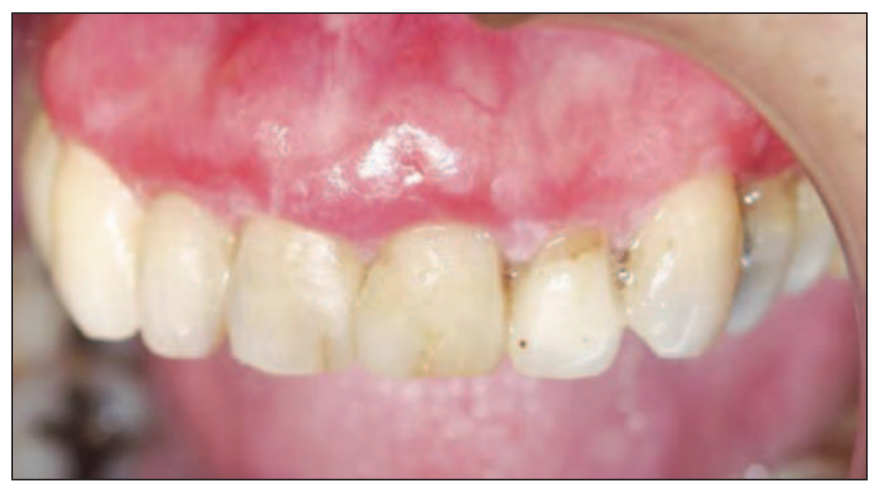

Fig. 5. Mucosa gingival maxilar superior.

el análisis periodontal. Se le realizó Índice gingival simplificado de Lindhe e Índice de higiene de O'Leary. Realizamos biopsia excisional de la mucosa palatina con bisturí frío que se remitió al patólogo.

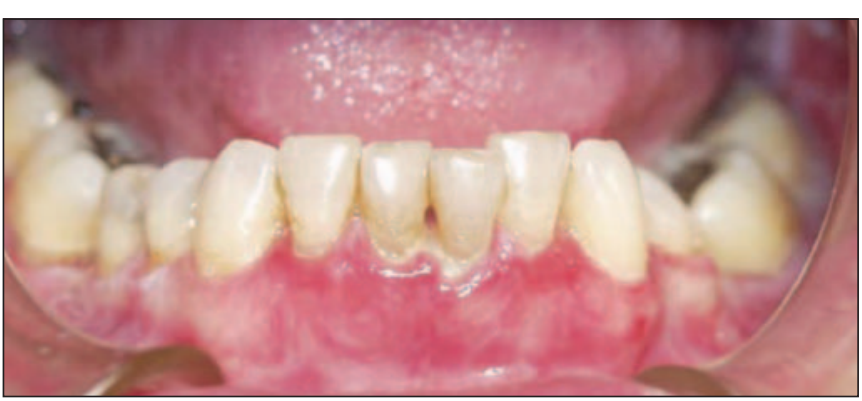

Fig. 6. Mucosa gingival maxilar inferior.

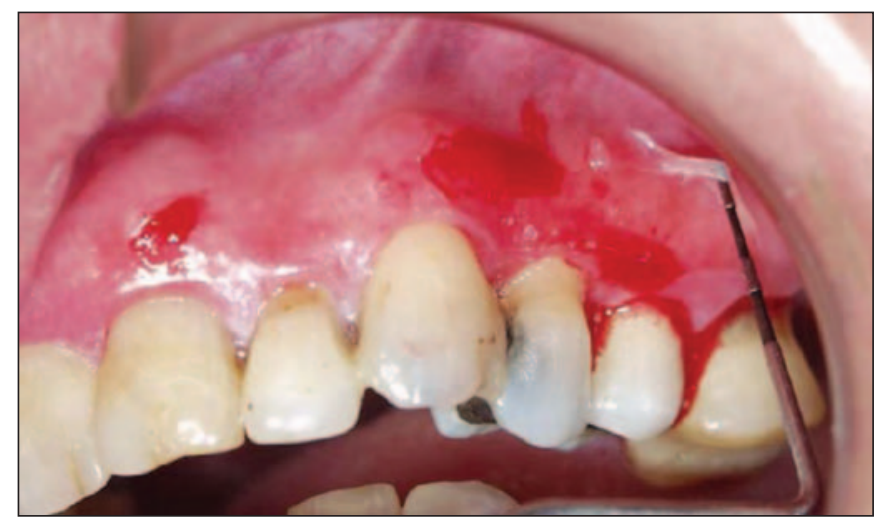

Fig. 7. Gingivitis descamativa.

\section{RESUILTADOS}

El diagnóstico de las lesiones fue clínico e histopatológico.

La histopatología de la biopsia mostró hiperqueratosis ortoqueratósica con hipergranulosis e hiperplasia epitelial con crestas interpapilares en dientes de sierra; acompañada de queratinocitos necróticos en las capas basales de la mucosa y presencia de cuerpos hialinos. El corion subyacente mostraba un infiltrado inflamatorio linfohistiocitario denso en banda, que borraba la unión cutáneo mucosa, existiendo, además, moderada fibrosis. El diagnóstico por tanto, fue consistente en liquen plano.

El primer tratamiento al que sometimos a la paciente fue a tratamiento periodontal básico (instrucciones en higiene oral y raspado y alisado radicular), ya que la mejora de la higiene oral y la eliminación de placa bacteriana se asocia con mejoras del liquen plano (14). El tratamiento paliativo del liquen plano 
consistió en corticoterapia tópica, basada en acetónido de triamcinolona en orabase que retiramos paulatinamente, no obteniendo mejoras clínicas en el proceso, pero sí disminuyendo las molestias.

La paciente fue sometida a un riguroso plan de seguimiento durante el cual se revisaban las lesiones periódicamente.

Diez años después de nuestra primera consulta, en el año 2006, la paciente nos indicó que tenía lesiones similares a nivel vaginal. Fue remitida al servicio de ginecología y obstetricia, y las lesiones vaginales fueron analizadas histopatológicamente confirmán-

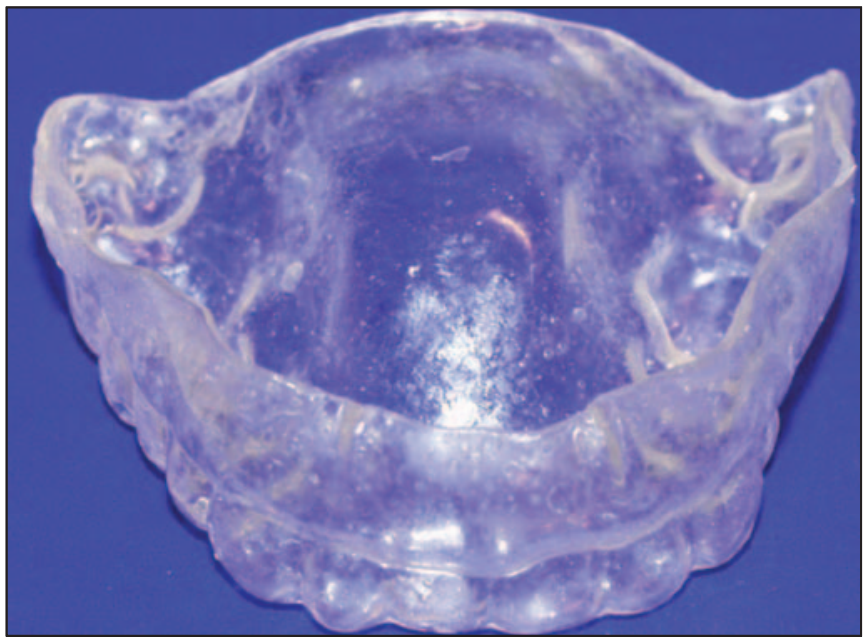

Fig. 8. Férula superior.

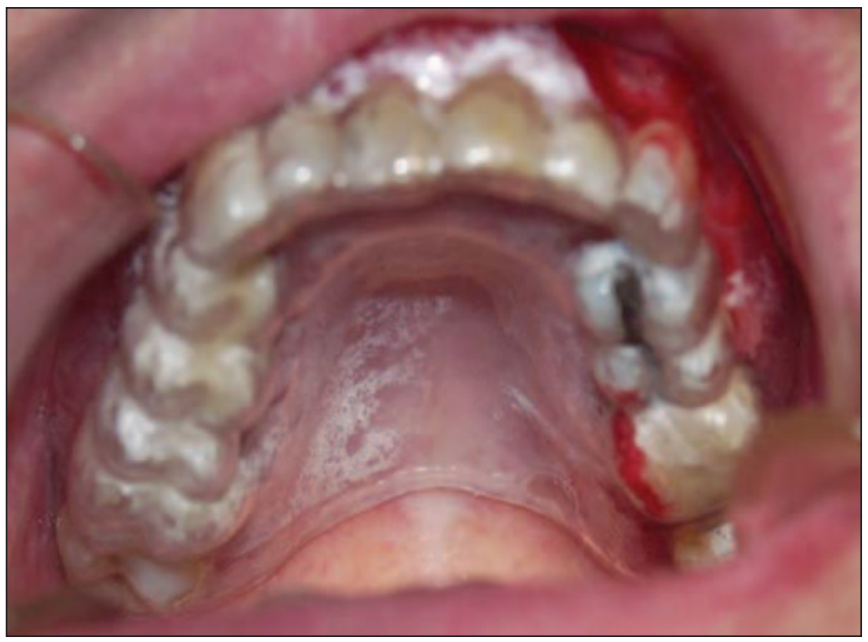

Fig. 9. Férula en boca. dose que se trataba también de liquen plano, diagnosticándose así el proceso como "síndrome vulvovaginal gingival del liquen plano”. Las lesiones genitales fueron produciendo tractos fibrosos que interrumpían la vagina y otros tractos fibrosos que se extendían a la pared posterior de la misma. Presentaba estenosis vaginal total, con fusión de los labios menores en toda su extensión.

Este nuevo cuadro, empeoró psíquicamente a la paciente, a la vez que las lesiones orales se hicieron más evidentes.

Tras ser intervenida quirúrgicamente en el servicio de ginecología para realizar vaginectomía y neovagina, se le recomendó tratamiento corticoideo tópico, basado en protopic al 0,1\% y una suspensión de dacortin, para las lesiones vaginales, se le dobló la dosis de antidepresivos (dumirox y trankimazin) pasando de tomar $75 \mathrm{mg}$ a $150 \mathrm{mg}$ y le realizamos unas férulas orales para la colocación del acetónido de triamcinolona en orabase al 0,2\% (Figs. 8-11).

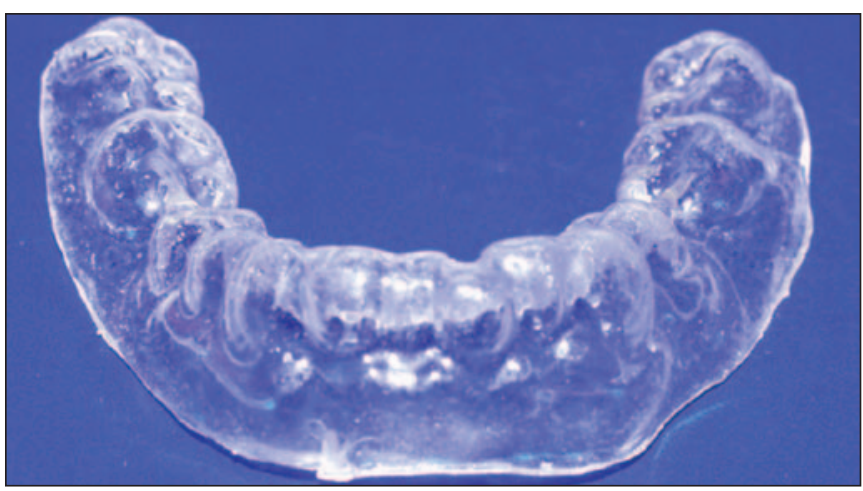

Fig. 10. Férula inferior.

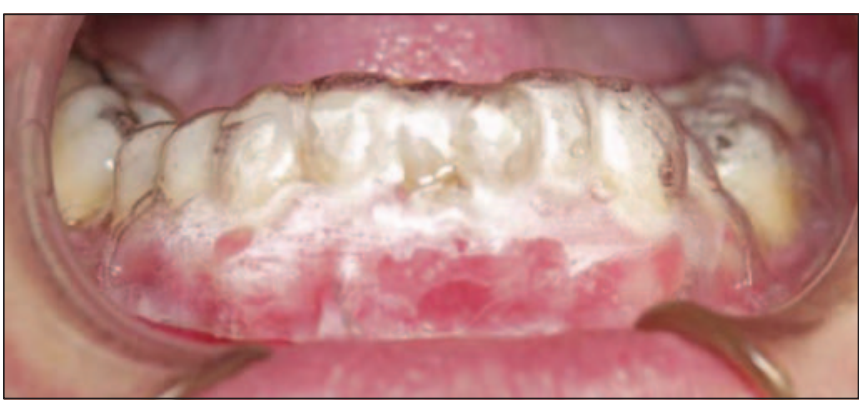

Fig. 11. Férula en boca. 
En la actualidad, año 2009, la paciente sigue siendo cuidadosamente vigilada para evaluar la evolución de las lesiones. Continuamos con el tratamiento de acetónido de triamcinolona en orabase al $0,2 \%$ colocado en las férulas durante 8 horas diarias, en intervalos intermitentes de 6 meses de duración, a la vez que su psicoterapeuta vigila la dosis de antidepresivos.

A día de hoy hemos conseguido estabilizar las lesiones, evitando que empeoren. Hemos conseguido paliar las lesiones erosivas, aunque mantenemos las lesiones blanquecinas, considerándose esta situación como un éxito del tratamiento (Figs. 12-15).

Su ginecólogo realiza exploraciones rutinarias para controlar la evolución de las lesiones vaginales, lo que junto

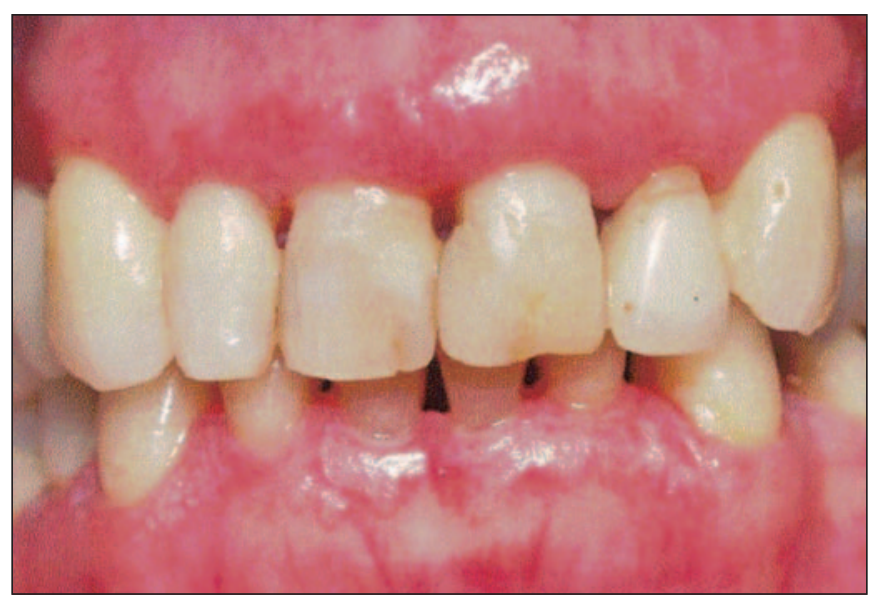

Fig 12. Mucosa gingival superior e inferior.

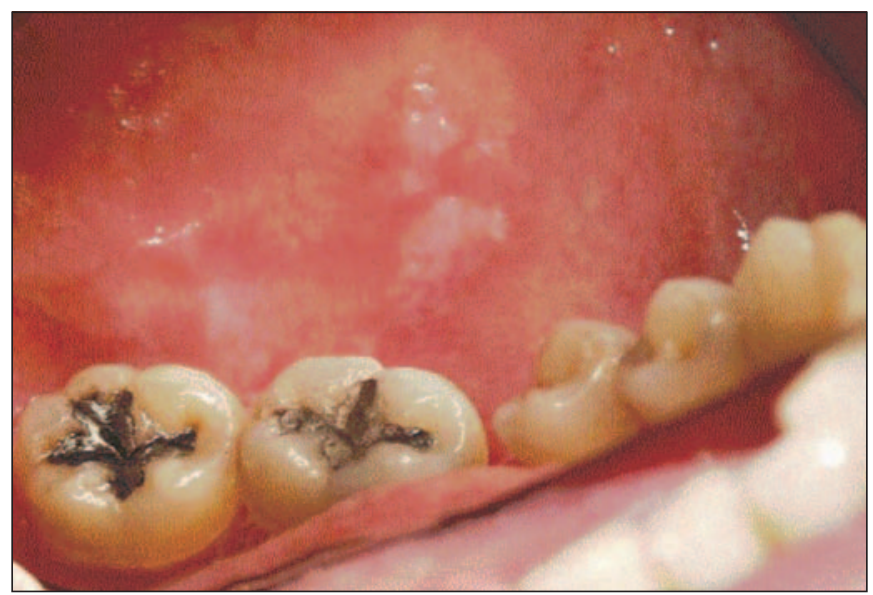

Fig 14. Dorso lingual. con el control dermatológico completa el círculo de profesionales médicos que controlamos a la paciente.

\section{DISCUSIÓN}

Aunque la prevalencia del liquen plano oral es menor al $4 \%$ y en su asociación con el síndrome vulvovaginal-gingival, la prevalencia es mucho menor (2), sin embargo puede intuirse y así se confirma en publicaciones actuales $(2-4,13,15)$ que las lesiones, con el transcurso de los años se desarrollan no sólo en la boca, sino también en otras mucosas.

Unido a esto está la posibilidad de malignización de las lesiones (5-12) y la afectación psicológica que

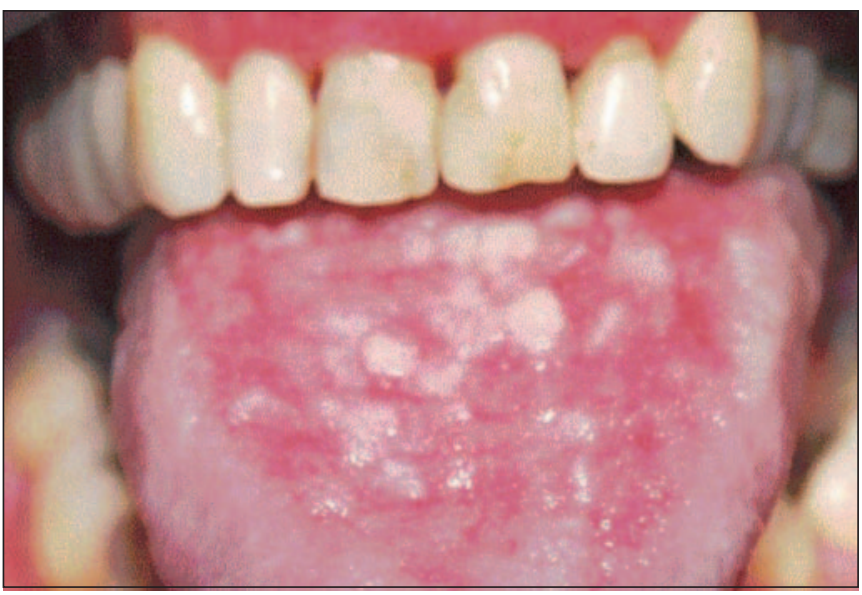

Fig 13. Mucosa yugal izquierda.

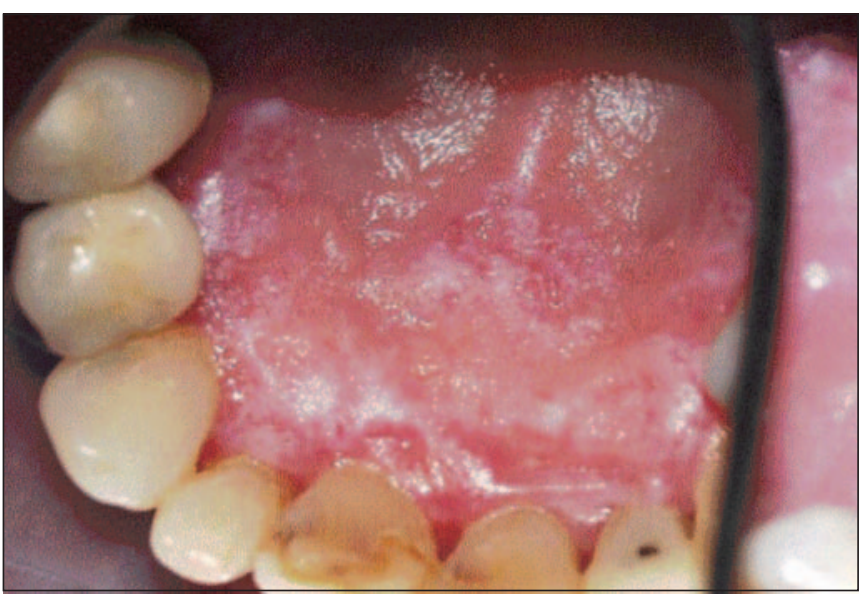

Fig 15. Mucosa palatina. 
tiene sobre el paciente, es por todo esto que nos parece de vital importancia detectar este tipo de lesiones y saber cómo actuar frente a ellas, con un correcto diagnóstico (no olvidar el papel determinante de la histopatología) y un tratamiento adecuado, para evitar futuros desenlaces no deseados.

\section{CONCLUSIÓN}

Los pacientes con lesiones de liquen oral deben ser vigilados y derivados a los especialistas correspondientes para descartar afectación de otras mucosas. Una vez obtenido el diagnóstico histológico hay que empezar el tratamiento adecuado (higiene oral, psicoterapia y corticoides fundamentalmente).

\section{BIBLIOGRAFÍA}

1. Blanco Carrión A. Liquen plano oral. Madrid: Ediciones Avances Médico-Dentales, S.L. 2000.

2. Matesanz-Pérez P, Bascones-Martínez A. Liquen plano: Revisión de la literatura actual. Av Odontoestomatol 2009;25(2):99-114.

3. Setterfield JF, Neill S, Shirlaw PJ. The vulvovaginal syndrome: a severe subgroup of lichen planus with characteristic clinical features and a novel association with the class II HLA DQB1*0201 allele. J Am Acad Dermatol 2006 Jul; 55(1):98113.

4. Bermejo-Fenoll A, López-Jornet P. Liquen plano oral. Naturaleza, aspectos clínicos y tratamiento. RCOE 2004;9(3):395-400.

5. Bermejo-Fenoll A, López-Jornet P, Saura-Inglés A, Sánchez-Siles M. Liquen plano oral y lesión precancerosa: caso clínico. Revista COEA 2003; 15(4):10-5.

6. Cerero-Lapiedra R. Malignización del liquen plano oral. Av. Odontoestomatol 2008;24(1):97-103.

7. Petti PF, Bagán JV, Scully C, Chaparro N. Transformación maligna del liquen plano oral en tres nuevos casos. Acta Otorrinolaringol Esp 2004;55: 41-44.

8. Van Der Meij EH, Mast H, Van Der Waal I. The posible premalignant carácter of oral lichen planus and oral lichenoid lesions: a prospective five-year follow-up study of 192 patients. Oral Oncol 2007 Sep;43(8):742-8.

9. Lozada Nur F, Miranda C. Oral lichen planus: epidemiology, clinical characteristics, and associated diseases. Semin Cutan Med Surg 1997 Dec;16(4):273-7.

10. Eisen D. The clinical features, malignant potential, and systemic associations of oral lichen planus; a study of 723 patients. J Am Acad Dermatol 2002 Feb;46(2)207-14.

11. Mignona MD, Lo Russo L, Fedele S, Ruppo E. Clinical behaviour of malignant transforming oral lichen planus. Eur J Surg Oncol 2002;28(8): 838-43.

12. Bermejo-Fenoll A, Sanchez-Siles M, López-Jornet P. Premalignant nature of oral lichen planus. A retrospective study of 550 oral lichen planus patients from south-eastern Spain. Oral Oncol 2009 Apr 8.

13. Blanco Carrión A, Otero Rey E, Peñamaría Mallón M, Diniz Freitas M. Diagnóstico del liquen plano oral. Av Odontoestomatol 2008;24(1):11-31.

14. Tejedor B, Larrea G, Cortés D. Estado periodontal en pacientes con enfermedad liquenoide oral ulcerativa: análisis de 22 casos consecutivos. Period y Osteoin 2008; 14(4):259-62.

15. Costa H, Santibáñez V, Scavino Y. Tratamiento de liquen escleroso vulvar con tacrolimus tópico: resultado y seguimiento. Folia dermatol. Peru 2005;16(1):29-32.

\section{CORRESPONDENCIA}

\author{
A. Alonso Rosado \\ angelalonso1955@gmail.com
}

